\title{
The effect of varying specimens' printing angles to the bed surface on the tensile strength of 3D-printed 17-4PH stainless-steels via metal FFF additive manufacturing
}

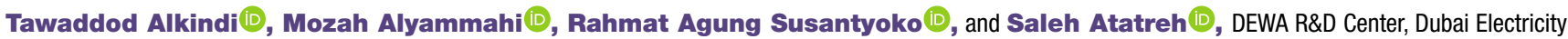 \\ and Water Authority, P.0. Box 564, Dubai, UAE \\ Address all correspondence to Rahmat Agung Susantyoko at rahmat.susantyoko@dewa.gov.ae
}

(Received 4 February 2021; accepted 13 April 2021; published online: 7 May 2021)

\begin{abstract}
We fabricated 17-4PH stainless-steel specimens via Fused Filament Fabrication (metal FFF). Then, we studied the effect of varying specimens' printing angles to the bed surface (part orientation) by analyzing the tensile test and scanning electron microscopy results. We found anisotropy, where specimens printed at $90^{\circ}$ exhibited the lowest tensile-stress-at-maximum-load of $440.15 \mathrm{MPa}$ and elongation-at-break of $0.83 \%$, compared to specimens printed at $0^{\circ}$ of $947.26 \mathrm{MPa}$ and $2.98 \%$, respectively. We recommend printing angles from $0^{\circ}$ to $10^{\circ}$ to achieve optimum tensile strengths. This study is significant in ensuring quality for the deployment and scale-up of spare-part production via metal FFF.
\end{abstract}

\section{Introduction}

Additive manufacturing (AM) has the advantage of giving users the ability to create bespoke designs of both different geometric and different materials. AM applications cover prototyping, tooling, performance improvement, personalization, spare-part, maintenance, and repair. At Dubai Electricity and Water Authority (DEWA), we are interested in the 3D printing of stainless-steel metal material for the deployment and scale-up of spare-part application, with an example use-case of replacement of obsolete metal parts.

Some of the additive manufacturing technologies for printing metal parts are powder bed fusion (PBF), directed energy deposition (DED), and fused filament fabrication (FFF). ${ }^{[1]}$ The PBF has the advantage of fine printing resolution but relatively slow deposition. The DED has the advantage of relatively fast printing (high build rate) but achieves only a near-net shape (coarse printing resolution). The FFF process has a balanced performance with a relatively good resolution, an acceptable printing time, and a reasonably low operation cost. FFF is suitable for our specific use-case for the spare-part application. While the FFF additive manufacturing was originally applied for pure polymers (without filler), the literature review showed the prospect of adding carbon composite, ceramic, or metal fillers at high concentrations. ${ }^{[1,2]}$

Herein, we defined the term "metal FFF" as the additive manufacturing of metals utilizing the FFF process. Other similar terms reported in the literature were the fused deposition of metals (FDMet), multiphase jet solidification (MJS), material extrusion additive manufacturing (MEAM), or atomic diffusion additive manufacturing (ADAM) process. Throughout this paper, we used the "metal FFF" term for consistency and to avoid confusion.

There were at least two types of stainless-steel materials reported in the FFF literature: $316 \mathrm{~L}$ stainless-stee ${ }^{[3-6]}$ and 17-4PH stainless-steel. ${ }^{[7-13]}$ Greul et al. ${ }^{[7]}$ reported metal FFF process using filament feedstocks made from a mixture of metal powder and binder, followed by layered deposition, debinding, and sintering. Danforth's research group ${ }^{[8,9]}$ reported metal FFF process utilizing four components of the binder: elastomer, tackifier, wax, and polymer. The development of multicomponent binders was among the critical success factor for the metal FFF process. ${ }^{[1]}$ Although many reported binder compositions were proprietary, reference ${ }^{[1]}$ hinted at some of the binder compositions.

Gonzalez-Gutierrez et al. ${ }^{[10]}$ investigated the extrusion temperature, flow rate multipliers, and speed multipliers for FFF of 17-4PH stainless-steel. Proprietary binder consisted of thermoplastic elastomer, polyolefin-based backbone polymer, and compatibilizer were used. ${ }^{[10]}$ Gonzalez-Gutierrez et al. ${ }^{[10]}$ observed an optimized extrusion temperature of $260{ }^{\circ} \mathrm{C}$, flow rate multiplier of $200 \%$, and printing rate multiplier of $100 \%$ in their case. Gonzalez-Gutierrez et al. also investigated the tensile strength of 17-4PH stainless-steel using proprietary binder based on grafted polyolefin and thermoplastic elastomer material. ${ }^{[1]}$ The average Young's modulus was $196 \mathrm{GPa}$, the average maximum stress was $696 \mathrm{MPa}$, and the strain at break was $4 \%$. ${ }^{[1]}$

Godec et al. optimized the extrusion temperature, flow rate multiplier, and layer thickness of FFF process parameters of 17-4PH stainless-steel. ${ }^{[12]}$ The filament composition was 55 
vol\% of 17-4PH stainless-steel powder in multicomponent binder systems. ${ }^{[12]}$ Galati et al. investigated the density, roughness, and accuracy of 3D-printed 17-4PH stainless-steel using metal FFF process utilizing a commercial metal 3D printer system from Markforged ${ }^{\mathrm{TM}}$ company. ${ }^{[13]}$ The advantage of the commercial metal 3D printer system is the user-friendliness of the process, with ready-to-use proprietary binders, ready-touse proprietary metal filament formulation, and ready-to-use proprietary multi-step sintering temperature recipe.

Our motivation in performing this study is as follows. We have printed metal spare parts for DEWA operations on a pilot basis, using the same commercial metal 3D printer mentioned in reference ${ }^{[13]}$ As we saw the benefits to the DEWA operations, to scale-up the printing for more quantities and more metal part's designs, we need to establish stringent quality checks. However, to our knowledge, there is only one reported paper ${ }^{[13]}$ utilizing this commercial metal 3D printer system. Therefore, we studied the effect of the printing process on the mechanical performance of the 3D-printed part. Specifically, we investigated the tensile mechanical strength property of 3D-printed 17-4PH stainless-steel using the metal FFF process by varying the specimen printing angles.

The novelty of this study is that, to our knowledge, we reported for the first time the anisotropic behavior of 17-PH stainless-steel specimens manufactured via metal FFF additive manufacturing. This study's impact is significant in ensuring the 3D printing quality for the deployment and scale-up of spare-part production via metal FFF additive manufacturing.

\section{Methodology Materials}

We used a Metal-X 3D printer system (Markforged ${ }^{\mathrm{TM}}$, USA) to conduct this work. Commercially available 17-4PH stainless-steel filaments (Markforged ${ }^{\mathrm{TM}}$, USA) with a diameter of $1.75 \mathrm{~mm}$ were used to print all the specimens. The filaments consist of stainless-steel material with a proprietary binder. During storage, the 17-PH stainless-steel filament spools were stored vertically inside packaging boxes as per manufacturer recommendation and due to the spool material's fragility at room temperature.

\section{D printing processes}

Dog-bone-shaped tensile test specimens were used. The geometry of the specimens is shown in Fig. S1 (Electronic Supplementary Material; Online Resource). Eiger software (Markforged $^{\mathrm{TM}}$, USA) was utilized to import the STL file of the specimen design. The setting used in the Eiger software were as follow: Material $=17-4$ stainless-steel, Furnace type $=$ Sinter-1, Printer type $=$ Metal Series $($ Metal-X), Post-Sintered Layer Height $(\mathrm{mm})=0.125$, Sinter Stability $=$ Yes, Use Raft $=$ Yes, Infill $=$ Solid Fill, Wall Layers $(1 \mathrm{~mm}$ post sintered $)=4$.
The printing processes consist of four phases: fused filament fabrication followed by washing, drying, and sintering. The schematic image can be found in Fig. S2 (Electronic Supplementary Material; Online Resource). The temperature parameters' values (chamber temperature, print bed temperature, and sintering temperatures) were not provided due to the proprietary or non-open-source characteristics of this equipment. The chamber temperature was warmer than room temperature in order for the spool material to be relatively flexible. The print bed consists of a temperature-controlled and vacuum-capable stage coupled with a disposable print sheet.

We investigated ten different print orientations, varying from $0^{\circ}$ to $90^{\circ}$ with an increment of $10^{\circ}$ for each print orientation angle. The $\mathrm{Y}_{0^{\circ}}$ specimen was printed with the configuration of $0^{\circ}$ printing angle to the print bed in $\mathrm{X}, \mathrm{Y}$, and $\mathrm{Z}$ axes. Throughout this work, the printing angle in the $\mathrm{X}$ and $\mathrm{Z}$ axes remained zero constantly, while the printing angle orientation in Y-axis was varied. An example of the specimen name nomenclature: when the printing angle was set at $10^{\circ}$ rotation with respect to Y-axis, the specimen name would be $\mathrm{Y}_{10^{\circ}}$. The details of the printed specimens were summarized in TABLE S1 (Electronic Supplementary Material; Online Resource). Figure 1 shows the illustration of varying the printing angle. For each printing angle, four specimens were fabricated for tensile testing purposes, and one specimen was fabricated for the investigation of the morphology.

\section{Mechanical tests}

The tensile test was carried out at room temperature using the Instron 3367 apparatus with Bluehill LE 3.77 software. The load cell was rated at a maximum of $30 \mathrm{kN}$. The tensile rate was set to $10 \mathrm{~mm} / \mathrm{min}$. The desired outputs obtained were: (i) elongation-at-break, (iii) tensile-stress-at-maximum-load (iii) tensile-stress-at-yield, and (iv) Young's modulus. Four specimens from each batch were used, in which their obtained values were averaged for each printing angle.

\section{Mass-reduction measurements}

The metal FFF technology has three states during the process. The "green part" is the state after the layered deposition, while the "brown part" is the state after the part goes through the debinding or washing stage. Finally, the "silver part" is the final state after the part is sintered and has metallic characteristics. ${ }^{14}$

The mass-reduction-after-washing measurement was conducted by calculating the difference in the mass of the specimens before washing (green mass) and after washing (brown mass), refer to Eq. 1. The relative density was calculated from the mass-reduction-after-washing data, refer to Eq. 2.

$$
\text { Mass reduction } \%=\frac{\text { Green mass }- \text { Brown mass }}{\text { Green mass }} \times 100 \%
$$

Relative density $=100 \%-$ Mass reduction $\%$ 


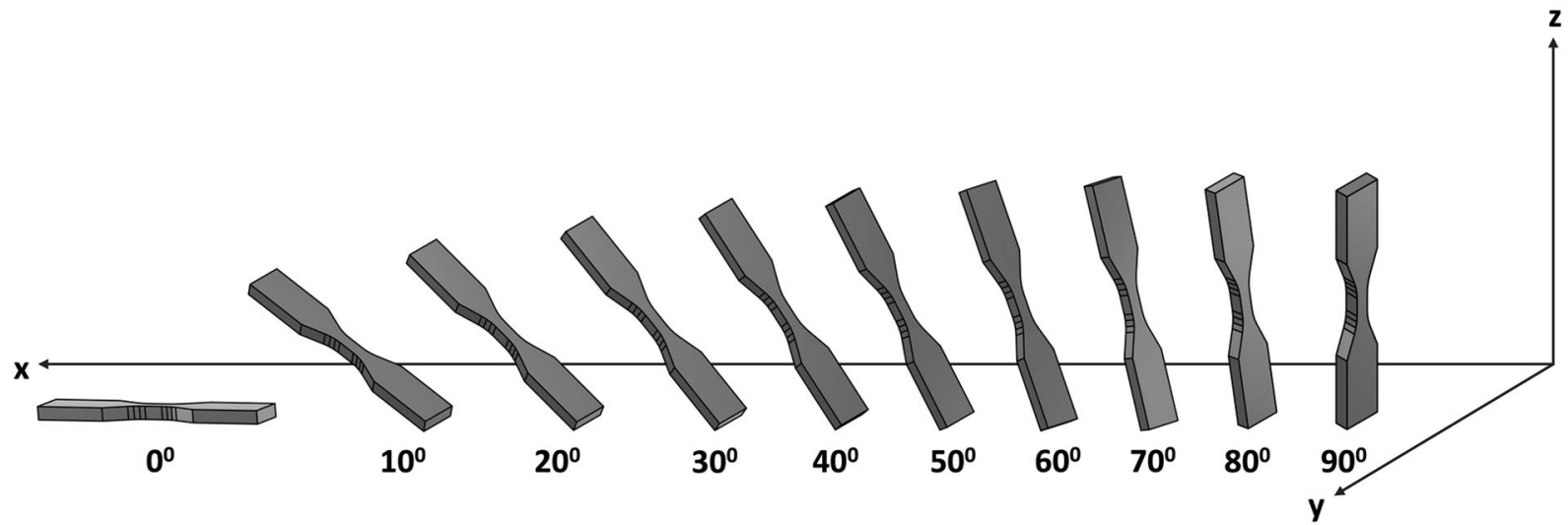

Figure 1. Illustration of changing the printing angle, rotated with respect to y-axis by $0^{\circ}, 10^{\circ}, 20^{\circ}, 30^{\circ}, 40^{\circ}, 50^{\circ}, 60^{\circ}, 70^{\circ}, 80^{\circ}$ and $90^{\circ}$. All specimens have the same dimensions but different printing angles.

\section{Imaging (top-view) of as-sintered specimens}

Scanning electron microscopy (SEM) was conducted using Tescan VEGA XM SEM to examine the morphology of the layers of printed dog-bone specimens. The operation was conducted under the following conditions: $50 \times$ magnification, $20 \mathrm{kV}$ accelerating voltage, secondary electron mode, and high vacuum.

\section{Imaging (cross-section) of as-sintered specimens}

The internal structure of the printed specimens before tensile testing was observed by cutting the specimen for a brittle fracture. Obtaining a brittle fracture is necessary to preserve the internal geometry. ${ }^{[15]}$ Specimens were held for $1 \mathrm{~min}$ in liquid nitrogen until they were cooled to $-196{ }^{\circ} \mathrm{C}$. BS Charpy Impact equipment was used to break as-sintered specimens in half. After cutting, the morphology of the fracture was imaged using the FEI-ThermoFischer Quattro S SEM. The operation was conducted under the following conditions: $80 \times$ and $500 \times$ magnifications, $20 \mathrm{kV}$ accelerating voltage, secondary electron mode, and high vacuum.

\section{Imaging (cross-section) of specimens after tensile testing}

The fracture cross-sections after the tensile test were investigated using Tescan VEGA XM SEM to observe the internal pattern and the fracture morphology. The operation was conducted under the following conditions: $50 \times$ and $500 \times$ magnifications, $20 \mathrm{kV}$ accelerating voltage, secondary electron mode, and high vacuum.

\section{Results and discussion}

The anisotropy in the mechanical property of polymer (without additive) using FFF is well-known; for example, Acrylonitrile Butadiene Styrene (ABS) 3D-printed part has higher strength when printed horizontally than vertically due to relatively weak adhesion strength between layers. ${ }^{[15]}$ We are interested in answering the questions: whether metal FFF (e.g., 17-4PH stainless-steel) has similar anisotropy behavior compared to polymer FFF (e.g., ABS) and whether the trend is dominated by the filament material or by the FFF characteristic.

The morphology of the specimens was checked using SEM; see the location in Fig. S3 (Electronic Supplementary Material; Online Resource). At 50 times magnification, the top surfaces of the middle-section of dog-bone-shaped printed specimens were observed, as shown in Fig. 2. It can be seen that varying the printing angle changed the appearance of the 3D-printed specimens. At a print angle of $0^{\circ}\left(\mathrm{Y}_{0^{\circ}}\right)$, there was a visible difference in the appearance of the surface, which attributed to the toolpath functionality of the printing software at that particular angle; see Fig. S4 (Electronic Supplementary Material; Online Resource). As the printing angle was increased, the produced specimens had perpendicularly defined deposited layers with the height of $0.72,0.37,0.25,0.19,0.17,0.14,0.13,0.13$, and $0.12 \mathrm{~mm}$ for $\mathrm{Y}_{10^{\circ}}, \mathrm{Y}_{20^{\circ}}, \mathrm{Y}_{30^{\circ}}, \mathrm{Y}_{40^{\circ}}, \mathrm{Y}_{50^{\circ}}, \mathrm{Y}_{60^{\circ}}, \mathrm{Y}_{70^{\circ}}, \mathrm{Y}_{80^{\circ}}$, and $\mathrm{Y}_{90^{\circ}}$, respectively, as shown in Fig. $2 \mathrm{~b}$ to $\mathrm{j}$.

Figure 3 provides the graphical comparison of tensile properties. The histograms showed the average value, while the whiskers showed the maximum and minimum value for each batch, as seen in Fig. $3 b$ to e. Tabulated data can be found in TABLE S2 (Electronic Supplementary Material; Online Resource). There was a noticeable difference in the tensile properties. As an example [see Fig. 3(a)], the tensile stress-strain curve shows that $\mathrm{Y}_{0^{\circ}}$ and $\mathrm{Y}_{10^{\circ}}$ recorded the highest values of tensile-stressat-maximum-load, which were 947.26 and $949.87 \mathrm{MPa}$, respectively. However, larger printing angles such as $60^{\circ}, 70^{\circ}, 80^{\circ}$, and $90^{\circ}$ exhibited significantly lower stress values of 418.12 , $415.28,488.88$, and $440.15 \mathrm{MPa}$, respectively. Specimen $\mathrm{Y}_{0^{\circ}}$ and $\mathrm{Y}_{10^{\circ}}$ exhibited the highest elongation-at-break of approximately $2.98 \%$ and $2.2 \%$, respectively, however specimen $\mathrm{Y}_{60^{\circ}}$, $\mathrm{Y}_{70^{\circ}}, \mathrm{Y}_{80^{\circ}}, \mathrm{Y}_{90^{\circ}}$ showed relatively low elongation-at-break of $0.87 \%, 0.60 \%, 1.07 \%$, and $0.83 \%$, respectively. The relative 

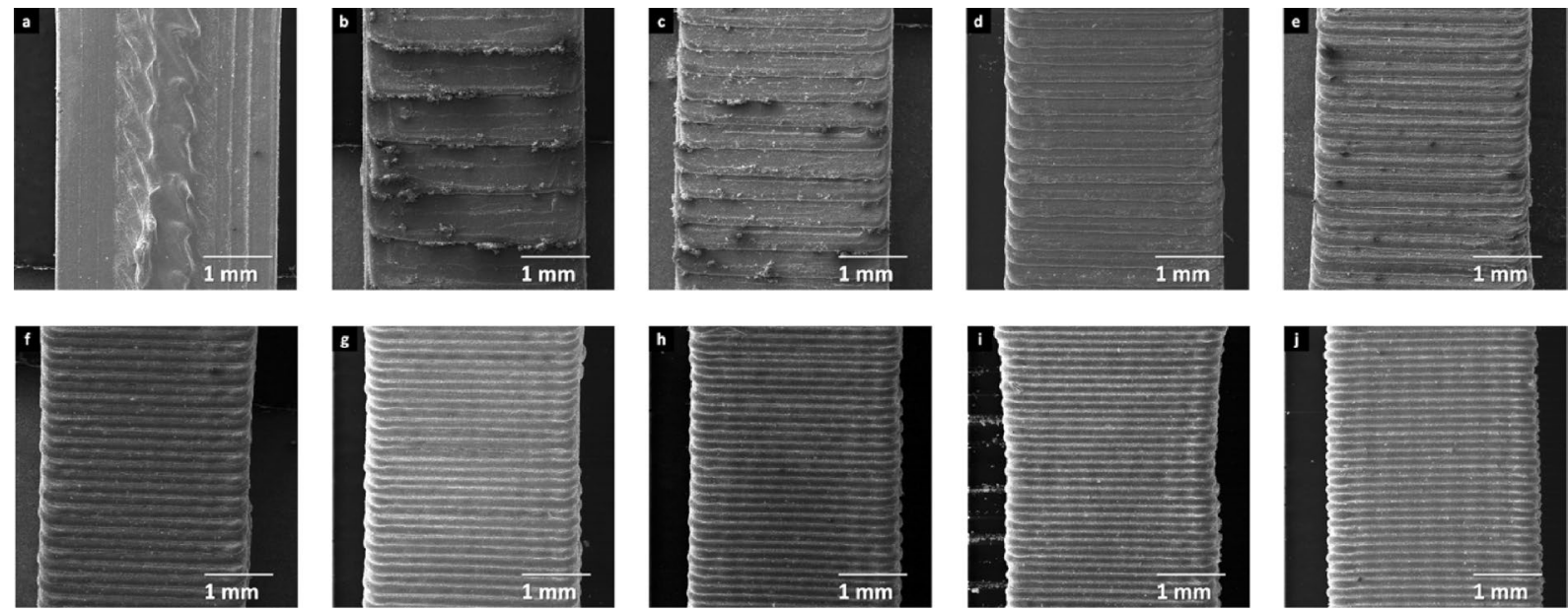

Figure 2. Top-view of the middle-section of dog-bone-shaped as-sintered 3D-printed specimens at different printing angles of: (a) $0^{\circ}$, (b) $10^{\circ}$, (c) $20^{\circ}$, (d) $30^{\circ}$, (e) $40^{\circ}$, (f) $50^{\circ}$, (g) $60^{\circ}$, (h) $70^{\circ}$, (i) $80^{\circ}$, (j) $90^{\circ}$.
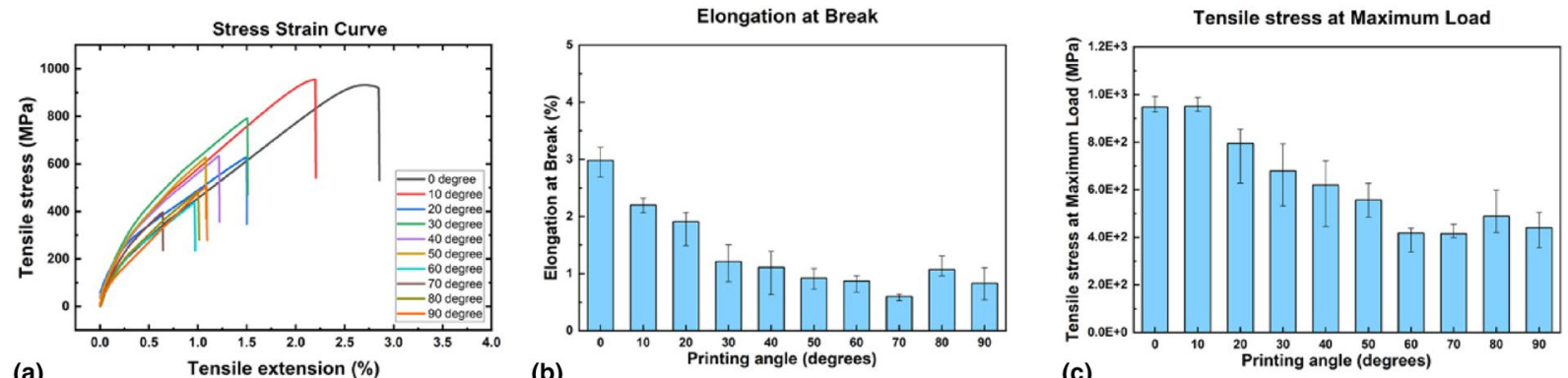

(b)

(c)

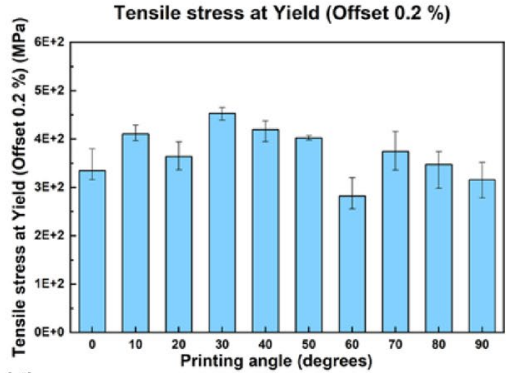

(d)

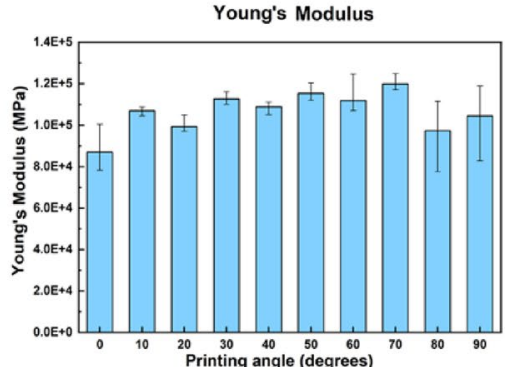

(e)

Figure 3. Mechanical properties represented in (a) stress-strain curve, (b) elongation at break, (c) tensile stress at maximum load, (d) tensile stress at yield (offset $0.2 \%$ ), and (e) Young's modulus. For (b-e), the histograms represent the average value, while the whiskers represent the maximum and minimum value for each batch.

standard deviation of tensile-stress-at-maximum-load was 32.77 while being 54.82 for elongation-at-break. This explained the extent of high anisotropy of the tensile-stress-at-maximum-load and elongation-at-break parameters of the specimens. The FFF characteristic dominated the tensile-stress-at-maximum-load and elongation-at-break. Several factors affect the quality of the fabricated specimens using material extrusion FFF additive manufacturing: extrusion temperature, infill rate, material flow, cooling rate post printing, and build orientation. ${ }^{[16-19]}$ These factors influence the geometric precision of the 3D-printed metal specimens, thus affecting the mechanical properties. ${ }^{[16-19]}$

We observed that the tensile-stress-at-yield and Young's modulus had no anisotropy trends. Tensile stress at yield and Young's modulus of all specimens showed close readings, with small values of the relative standard deviation of 16.13 and 9.15 , respectively. 
The morphology of the specimens at 5,000 times magnification showed the presence of microscopic pores in all specimens of $\mathrm{Y}_{0^{\circ}}$ to $\mathrm{Y}_{90^{\circ}}$, see Fig. S5 (Electronic Supplementary Material; Online Resource). The diameter of microscopic pores ranged from $1.2 \mu \mathrm{m}$ to $3.4 \mu \mathrm{m}$. It could be attributed to the debinding of the binder that induced pores. ${ }^{[1,7]}$ Fig. S6 (Electronic Supplementary Material; Online Resource) shows the average range of mass-reduction-after-washing varied between $4.13 \%$ to $4.25 \%$ among the specimens; i.e., the relative density varied between $95.75 \%$ to $95.87 \%$. We found little or no correlation between the mass-reduction-after-washing and the tensile properties (elongation-at-break, tensile-stress-at-maximum-load, tensilestress-at-yield, Young's modulus). It indicated that in this case, other FFF printing parameter(s) had a more substantial influence on the tensile properties, which was the air-gap parameter as explained in the next paragraph.

Figure S7 (Electronic Supplementary Material; Online Resource) shows the location of the cross-section. The crosssection of the specimens was checked using SEM. Figure 4 shows the cross-section view of the fracture (without undergoing tensile test) of the specimens revealed triangular-shaped or diamond-shaped openings (air gaps) with the approximate size of $\sim 50 \mu \mathrm{m}$ to $\sim 100 \mu \mathrm{m}$. These air gaps were attributed to the underfill between deposited toolpath lines of the walls. We observed that different printing angles produced different airgap directions with respect to the tensile test loading direction. Different printing angles also produced different shapes of air gaps. At low printing angles, such as $0^{\circ}$ and $10^{\circ}$, the air gaps have a triangular shape, spatially separated, and having a relatively small area, see Fig. 4a and b. At intermediate printing angles, such as $20^{\circ}$ to $50^{\circ}$, the air gaps have a diamond shape, spatially separated, and having a relatively intermediate area, see Fig. $4 \mathrm{c}$ and $\mathrm{f}$. At large printing angles, such as $60^{\circ}$ to $90^{\circ}$, the air gaps have a line or rectangular shape, spatially connected, and having a relatively large area, see Fig. $4 \mathrm{~g}$ and $\mathrm{j}$. The effective cross-section of the specimens decreased with increasing printing angles due to the increase in the area of the air gaps. In addition, the air gaps provided sites for crack initiation, which were more prominent for specimens printed at high angles, such as $60^{\circ}$ to $90^{\circ}$. It explained the specimens printed at low printing angles had better tensile-stress-at-maximum-load than specimens printed at high printing angles.

We propose that the specimens' tensile properties can be improved in the future if the air gaps are covered. Reference ${ }^{[10,15]}$ showed that increasing the flow rate multiplier (extrusion multiplier) or decreasing the layer thickness could minimize the presence of air gaps. Figure S8 (Electronic Supplementary Material; Online Resource) shows the cross-section view of the post-mortem specimens after the tensile test. It also showed the presence of air gaps, relevant to the finding in Fig. 4.

\section{Conclusion}

We have investigated the effect of varying specimens' printing angles on the tensile strength of 17-4PH stainless-steel parts via metal FFF additive manufacturing. The results showed that the specimens exhibited anisotropy. The ultimate tensile strength of the specimens varied with the changing of the printing angles. Specimens printed at $90^{\circ}$ to the print bed showed an ultimate tensile strength of $440.15 \mathrm{MPa}$, which was less than $50 \%$ of the ultimate tensile strength obtained of specimens printed at $0^{\circ}$ to the print bed. We also observed a similar trend for the specimens' elongation at break. Specimens printed at $90^{\circ}$ to the print bed showed $\sim 3.5$ times lower elongation at break, compared to specimens printed at $0^{\circ}$ to the print bed.

The anisotropy was attributed to the presence of air gaps, which existed due to extrusion underfill. Moreover, as the specimens' printing angle changed, the toolpath, number of layers, and the direction of load relative to the layers changed accordingly. While metal FFF additive manufacturing promises a balanced performance of good resolution, acceptable printing time, and reasonably low operation cost, further developments are required to reduce the air gaps between the extruded lines.

We recommend using printing angles of $0^{\circ}$ to $10^{\circ}$ to the print bed for 17-4PH stainless-steel material metal FFF additive manufacturing. This is because optimum tensile strengths were obtained for metal FFF when the printing angles were between $0^{\circ}$ to $10^{\circ}$. The $\mathrm{Y}_{0^{\circ}}$ specimens had an average of $947.26 \mathrm{MPa}$ of ultimate tensile strength and $2.98 \%$ of elongation at break, while $\mathrm{Y}_{10^{\circ}}$ specimens had an average of $949.87 \mathrm{MPa}$ of ultimate tensile strength and $2.20 \%$ of elongation at break. This study highlighted the importance of considering the printing angles to avoid any potential mechanical failure or deformation when the part is in operation.

\section{Acknowledgments}

We acknowledged Engineer Hayk Vasilyan for assisting in the cutting of specimens and Engineer Shashank Suvarn for assisting in the operation of FEI-ThermoFischer Quattro S SEM. We acknowledged the Center for Advanced Materials Research (University of Sharjah) for access to Tescan VEGA XM SEM. 

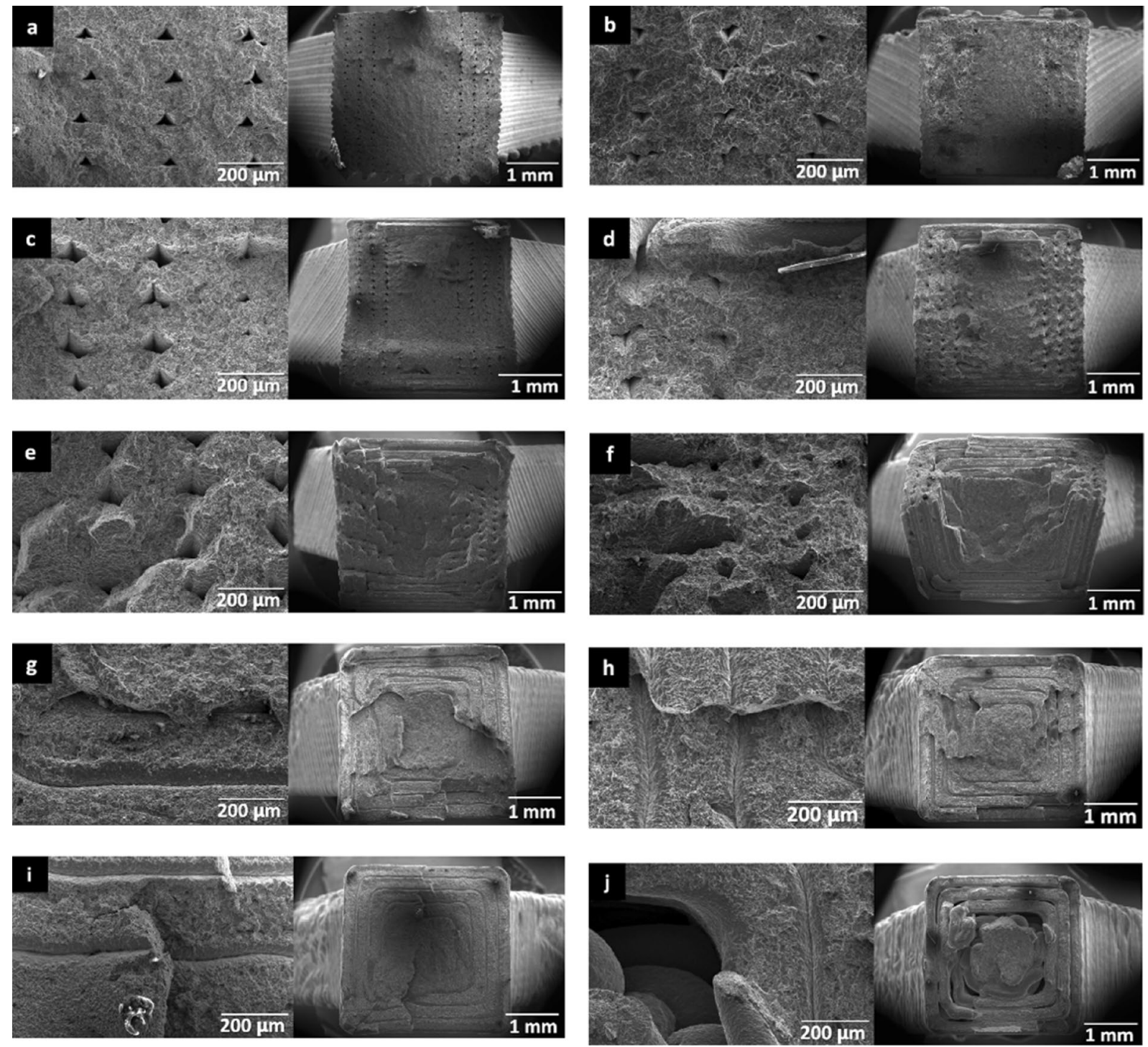

Figure 4. Cross-section view of the fracture of specimens without undergoing tensile test at different printing angles of: (a) $0^{\circ}$, (b) $10^{\circ}$, (c) $20^{\circ}$, (d) $30^{\circ}$, (e) $40^{\circ}$, (f) $50^{\circ}$, (g) $60^{\circ}$, (h) $70^{\circ}$, (i) $80^{\circ}$, (j) $90^{\circ}$.

\section{Author Contributions}

T. Alkindi, M. Alyammahi, and R.A. Susantyoko formulated the design of experiments. M. Alyammahi, S. Atatreh, and T. Alkindi conducted the metal FFF additive manufacturing experiments. M. Alyammahi and S. Atatreh tested the tensile mechanical strength of dog-bone-shaped specimens. T. Alkindi performed the analysis of the characterization data. R.A. Susantyoko wrote the introduction. T. Alkindi and M. Alyammahi wrote the methodology. R.A. Susantyoko supervised the works. All authors analyzed the data and contributed to the submitted manuscript.

\section{Data Availability}

Data to be made available on a reasonable request.

\section{Declarations}

\section{Conflict of interest}

All authors declare no conflict of interest.

\section{Open Access}

This article is licensed under a Creative Commons Attribution 4.0 International License, which permits use, sharing, adaptation, distribution and reproduction in any medium or format, as long as you give appropriate credit to the original author(s) and the source, provide a link to the Creative Commons licence, and indicate if changes were made. The images or other third party material in this article are included in the article's Creative Commons licence, unless indicated otherwise in a credit line to the material. If material is not included in the article's 
Creative Commons licence and your intended use is not permitted by statutory regulation or exceeds the permitted use, you will need to obtain permission directly from the copyright holder. To view a copy of this licence, visit http://creativeco mmons.org/licenses/by/4.0/.

\section{Supplementary Information}

The online version contains supplementary material available at https://doi.org/10.1557/s43579-021-00040-0.

\section{References}

1. J. Gonzalez-Gutierrez, S. Cano, S. Schuschnigg, C. Kukla, J. Sapkota, C. Holzer, Additive manufacturing of metallic and ceramic components by the material extrusion of highly-filled polymers: a review and future perspectives. Materials (Basel) 11, 840 (2018). https://doi.org/10.3390/ ma11050840

2. A. Almazrouei, R.A. Susantyoko, C.-H. Wu, I. Mustafa, A. Alhammadi, S. Almheiri, Robust surface-engineered tape-cast and extrusion methods to fabricate electrically-conductive poly(vinylidene fluoride)/carbon nanotube filaments for corrosion-resistant 3D printing applications. Sci. Rep. 9, 9618 (2019). https://doi.org/10.1038/s41598-019-45992-5

3. P. Parenti, S. Cataldo, M. Annoni, Shape deposition manufacturing of $316 \mathrm{~L}$ parts via feedstock extrusion and green-state milling. Manuf. Lett. 18, 6-11 (2018). https://doi.org/10.1016/j.mfglet.2018.09.003

4. Y. Thompson, J. Gonzalez-Gutierrez, C. Kukla, P. Felfer, Fused filament fabrication, debinding and sintering as a low cost additive manufacturing method of 316L stainless steel. Addit. Manuf. 30, 100861 (2019). https:// doi.org/10.1016/j.addma.2019.100861

5. J. Damon, S. Dietrich, S. Gorantla, U. Popp, B. Okolo, V. Schulze, Process porosity and mechanical performance of fused filament fabricated $316 \mathrm{~L}$ stainless steel. Rapid Prototyp. J. 25(7), 1319-1327 (2019). https://doi. org/10.1108/RPJ-01-2019-0002

6. H. Gong, C. Crater, A. Ordonez, C. Ward, M. Waller, C. Ginn, Material properties and shrinkage of $3 \mathrm{D}$ printing parts using ultrafuse stainless steel 316LX filament. MATEC Web Conf. 249, 1-5 (2018). https://doi.org/10. 1051/matecconf/201824901001

7. M. Greul, T. Pintat, M. Greulich, Rapid prototyping of functional metallic parts. Comput. Ind. 28(1), 23-28 (1995). https://doi.org/10.1016/01663615(95)00028-5
8. M.K. Agarwala, R. Van Weeren, A. Bandyopadhyayl, P.J. Whalen, A. Safari, S.C. Danforth, Fused deposition of ceramics and metals : an overview. in Proc. Solid Free. Fabr. Symp., pp. 385-392. https://doi.org/10.15781/ T2NK36Q96 (1996)

9. G. Wu, N.A. Langrana, R. Sadanji, S. Danforth, Solid freeform fabrication of metal components using fused deposition of metals. Mater. Des. 23, 97-105 (2002). https://doi.org/10.1016/S0261-3069(01)00079-6

10. J. Gonzalez-Gutierrez, R. Guráň, M. Spoerk, C. Holzer, D. Godec, C. Kukla, 3D printing conditions determination for feedstock used in fused filament fabrication (FFF) of 17-4PH stainless steel parts. Metalurgija 57, 117-120 (2018)

11. J. Gonzalez-Gutierrez, F. Arbeiter, T. Schlauf, C. Kukla, C. Holzer, Tensile properties of sintered $17-4 \mathrm{PH}$ stainless steel fabricated by material extrusion additive manufacturing. Mater. Lett. 248, 165-168 (2019). https://doi.org/10.1016/j.matlet.2019.04.024

12. D. Godec, S. Cano, C. Holzer, J. Gonzalez-Gutierrez, Optimization of the 3D printing parameters for tensile properties of specimens produced by fused filament fabrication of 17-4PH stainless steel. Materials (Basel) 13, 774 (2020). https://doi.org/10.3390/ma13030774

13. M. Galati, P. Minetola, Analysis of density, roughness, and accuracy of the atomic diffusion additive manufacturing (ADAM) process for metal parts. Materials (Basel) 12, 150 (2019). https://doi.org/10.3390/ma1224122

14. T. Kurose et al., Influence of the layer directions on the properties of $316 \mathrm{~L}$ stainless steel parts fabricated through fused deposition of metals. Materials (Basel) 13, 2493 (2020). https://doi.org/10.3390/ma13112493

15. B. Rankouhi, S. Javadpour, F. Delfanian, T. Letcher, Failure analysis and mechanical characterization of 3D printed ABS with respect to layer thickness and orientation. J. Fail. Anal. Prev. 16, 467-481 (2016). https:// doi.org/10.1007/s11668-016-0113-2

16. A. Alafaghani, A. Qattawi, B. Alrawi, A. Guzman, Experimental optimization of fused deposition modelling processing parameters: a design-formanufacturing approach. Procedia Manuf. 10, 791-803 (2017). https:// doi.org/10.1016/j.promfg.2017.07.079

17. C.Y. Lee, C.Y. Liu, The influence of forced-air cooling on a 3D printed PLA part manufactured by fused filament fabrication. Addit. Manuf. 25, 196-203 (2019). https://doi.org/10.1016/j.addma.2018.11.012

18. A. Boschetto, L. Bottini, Accuracy prediction in fused deposition modeling. Int. J. Adv. Manuf. Technol. 73, 913-928 (2014). https://doi.org/10.1007/ s00170-014-5886-4

19. L. Santana, J. Lino Alves, A. da Costa Sabino Netto, A study of parametric calibration for low cost 3D printing: seeking improvement in dimensional quality. Mater. Des. 135, 159-172. (2017). https://doi.org/10.1016/j.matdes.2017.09.020 